\title{
The architectures of data and information: Their confounded confusion
}

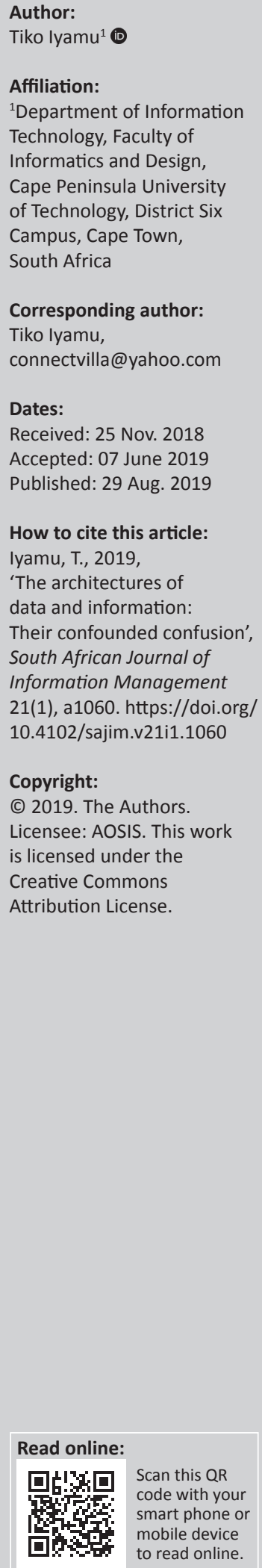

Background: Even though it is well documented in the academic domain, including various English dictionaries, that data and information are not the same thing, with the latter being a refinement of the former, many people within organisations and academic environments continue to loosely and interchangeably use these terms. This is a challenge that extends to the enterprise architecture discipline, which has an impact on how the domains of data and information architectures are defined, developed and implemented in many organisations.

Objectives: The challenge leads to misunderstanding of both technical and business requirements, as well as confusion about the differentiation between data and information architectures. This challenge affects the accomplishment of either data or information in an organisation. This is caused by the fact that data is referred to as information, meaning it has been refined, which is incorrect, and therefore affects requirements. Additionally, this challenge influences the organisational structure and the development of employees' career. Thus, the objective of this study was to examine the implication of practice in the loose and interchangeable use of the terms, 'data' and 'information', within an organisation.

Method: Based on this objective, the interpretivist stance was employed in the study. Qualitative data was gathered and the hermeneutics approach was employed in the analysis.

Results: From the analysis, a solution is proposed to halt further misconstruction of the architectures, and avoid the confusing challenges it has for organisations.

Conclusion: The study reveals what we need to know about the confounded confusion between data and information architectures. The differentiation between the two concepts can be of importance to professionals in the field of information systems and technologies as well as academics.

Keywords: Data architecture; information architecture; subjectivism; computing; information systems; qualitative methods.

\section{Introduction}

There is no business, government or social environment where data and/or information are not required or accessed for various reasons (Vick, Nagano \& Popadiuk 2015). Many organisations wholly depend on data and information for their competitiveness, sustainability and manageability of their activities (Grabara, Kolcun \& Kot 2014). However, the use of data or information can be confusing and complicated, specifically from design and support viewpoints. Such confusion may affect requirements gathering, development and implementation of systems and technologies (IS/IT) solutions (Fisher 2016). Thus, it is critical to understand the differences between the terms 'data' and 'information' particularly when employed from an architecture angle.

In the Oxford English Dictionary, the term 'data' is defined as 'facts and statistics used for reference or analysis' (Soanes 2002:275). Data are, therefore, facts that have little or no meaning. Fisher (2016) describes the term as meaningless facts that are neither right nor wrong, but processed and put into an understandable context. Kitchin (2014) argues that data is not a simple entity, as it seems to be more about the ideas, techniques, technologies, people and contexts that are necessary for the existence, processing, management, analysis and storage of data. Grabara et al. (2014) empirically admit that data are most of the time confused with information; however, it is very difficult to distinguish between them. Although Rein and Biermann (2013) also agree to the concept of confusion, they state that despite the use of the terms in an interchangeable fashion, the real meaning of data and information depends on the context. 
The refinement or transformation of data into meaningful entities is information. Again, in the Oxford English Dictionary, 'information' is defined as 'facts or knowledge that are provided or learned' (Soanes 2002:573), which can be considered epistemological. Grabara et al. (2014) argue that information is the means by which people obtain knowledge that leads to wisdom and understanding, and it is fundamental for proper management of organisational operations. Similarly, Vick et al. (2015) argue that information is the fundamental input for innovation and promotion of knowledge for both individuals and organisations.

From the viewpoint of fundamental vitality, governance and standardisation of data or information, it is important for an organisation to employ the architecture of the concepts. However, the architecture is even more complicated since the two concepts are closely related and, therefore, interchangeably used. In this type of confusion, architecture becomes even more critical because it defines an aggregate of consistent and well-defined principles that are used to guide an enterprise design (Hoogervorst \& Dietz 2015). Additionally, the architecture is used to define management structure, which includes how components and elements of an enterprise are interrelated, interconnected, organised and managed for an enterprise purposes (Safari, Faraji \& Majidian 2016). Thus, it is important to always differentiate between the data architecture and information architecture of an enterprise. The enterprise architecture (EA) is already a complex concept, necessitating the simplification of, and distinction between data and information architectures (Iyamu 2014). Hinkelmann et al. (2016:79) argue that the ISO/IEC/IEEE 42010 standard defines the EA as the 'fundamental concepts of properties of an enterprise in its environment embodied in its elements relationship and in the principle of its design and evolution'. Similarly, SaintLouis, Morency and Lapalme (2017) explain that there are many definitions of the term EA, which sometimes cause confusion when attempting to employ the concept. The confusion between data and information can only make the concept of EA more complicated. Additionally, this can make things more challenging for many organisations that depend on data and information for their businesses.

Moreover, information is crucial in development and implementation of systems and technologies, mainly because it aids and provides necessary elements during analysis, towards the goals of the EA (Farwick et al. 2013). Thus, the research question was as follows: what are the factors that differentiate data architecture from information architecture? The objective was, therefore, to address the confusion caused by the interchangeable use of the concepts in providing IS/IT solutions and management in an environment. Also, a better understanding of the implication of practice can assist in clarifying the differentiation between the concepts, towards adding value to an organisation. The remainder of this article explains the process and steps that were followed in achieving the objective of the study. First, I gathered and conducted a review of existing related literature as presented in the first section. The research methodology that was employed in the study is discussed in the second section. The analysis of the data is presented in the third section. In the fourth section, I explain the implications that the confusion caused by the loose and interchangeable use of the concepts in an organisation. This includes the implication of practice. Thereafter, a conclusion is drawn in the final section.

\section{Literature review: Data and information architecture}

Based on the objective of the study, a review of the related literature was conducted from both data architecture and information architectures' perspectives. The review focused on gaining an understanding of the concepts, from the scope, description to confusion viewpoints.

\section{Data architecture}

Data is a critical aspect of individuals', organisations', systems' and technologies' activities as has been demonstrated through social media and networking in the last decade (Grabara et al. 2014). According to Inmon and Linstedt (2014), data is the gasoline that fuels the computer since the first computer program was first written. The use, storage and management of data have shaped and transformed many organisations over the years, through support and enablement of architectural design. Thus, data architecture is singled out for academic studies (Inmon \& Linstedt 2014). According to You et al. (2015), the concept of 'data architecture' is defined as a composition of models, policies, rules and standards that define the collection, storage, management, integration and organisation of data. A data architect performs these tasks based on the requirements of the business (Shaw et al. 2016). The definition of data architecture enables and guides the employment of architects.

In some organisations, the scope of data architecture has expanded from determining the collection, storage and organisation of data to big data architecture, which involves design for large-scale big data solutions (Miller 2014). Mohammad, Mcheick and Grant (2014) claim that the scope of data architecture is not only limited to design but also to identifying and planning for communication with external and internal stakeholders. The above seems clear enough. However, Mark and Krishna (2014) argued that some of the roles of the data architect include the design, development and implementation of information architecture and data warehouses.

How are the above different from information and information architecture? This is the main question that led to this study to clarify the confusion and misunderstanding between the two concepts from architecture and computing perspectives.

\section{Information architecture}

Information architecture is a discipline that determines how information is presented in an appropriate way based 
on users' and environmental contexts (Toure, Michel \& Marty 2016). In the context, the term 'appropriate way' simply means the form in which information is organised or structured; this includes the flow, exchange and use (Pessoa et al. 2015). The authors went further to describe the organisation of information as defining the levels of details in a set of information which involves identifying components and grouping them into categories. According to Toure et al. (2016), the organisation of information is carried out purposely to identify, classify and determine how it can be used most effectively to achieve business goals and objectives. Thus, information architecture becomes very useful in many areas, such as the management of information challenges and ensuring that knowledge is presented in a structured and understandable manner to increase its purpose and usefulness within contexts (Iannuzzi et al. 2016). This is a task that is performed by an information architect from both organisational and technological perspectives.

The information architecture is not limited to designing single information spaces, such as websites and software applications; it also includes strategic use, aggregation and integration of multiple information spaces and their channels, modalities and platforms (Ding, Lin \& Zarro 2017). In addition, the information architecture includes providing standards that enable an organisation in their use, exchange and management (archives and libraries) of information (Joudrey \& Taylor 2017). In addition, in terms of development, information architecture can lead to the contextual inquiry and support the process of keeping track of development and implementation of IS/IT artefacts and solutions (Rojas \& Macías 2015).

\section{Understanding the confusion}

The confusion between data architecture and information architecture starts from the definition and the attributes of the concepts. According to Pras and Schönwälder (2003), it is often difficult to separate the attributes of data from those of information, which brings grey areas, as both concepts continue to overlap. Rossi and Hirama (2015), on the other hand, claim that it is within information architecture that data is reviewed to have meaning, value and usefulness. Despite this confusion, Molnár and Vincellér (2013) state that both information and data architectures are fundamental to any business, and represent the structure of the information that is required and used by an organisation. Such a lack of clear distinction wholly contributes to the confusion which both business people and IS/IT personnel encounter in the course of their duties, as well as career development.

In the management of networks, as well as defining objects within computing, there has always been confusion because of misunderstanding between data and information artefacts (Pras \& Schönwälder 2003). Aamodt and Nygård (1995) acknowledge that there was confusion between the terms 'data' and 'information' from the perspective of computing. The relationship between data and information is the main contributing factor to the confusion and misunderstanding
(Aamodt \& Nygård 1995; Kanehisa et al. 2013; Pras \& Schönwälder 2003). From a modelling angle, Pras and Schönwälder (2003) explain that there has been ongoing confusion about the differences between information and data.

Even though this only refers to data and information, and not the architectural aspect of the subjects, that is where the confusion and misunderstanding starts. Kanehisa et al. (2013) argue that the concept of 'data' and 'information', including knowledge, contributes to improving architecture from a database viewpoint. Even though the misunderstanding between data and information has long been identified, no proposed solution has yet been put forward. The few models that have been presented are abstracts. According to Aamodt and Nygård (1995), if a model leaves out many details, it is clearly an abstraction. It should be regarded as a foundation, and a basis for further discussions and development, which can lead to a possible solution.

\section{Research approach}

Based on the research question, which was to explore the factors that differentiate data architectures from information architectures, the answer cannot be objective or positivistic. The positivist approach is about obtaining knowledge through empirical observation and measures and assumes that there is a possibility to predict human activities. As such, the approach often leads to the use of quantitative research methods, which focuses on discovering measurable and quantifiable information (Chipangura, Van Niekerk \& Van der Waldt 2016). As this study is about addressing the confusion caused by the interchangeable use of the data and information architectures in an environment, the positivist and quantitative methods were not suitable. The qualitative methods were instead employed in this study from the interpretive perspective. Palinkas et al. (2015) state that qualitative methods enable a study to explore in detail the phenomena being studied. Also, the qualitative method provides the opportunity for discussion, through which complexities are explained and new topics emerge (Marshall et al. 2015), such as the confusion explored in this study. Iyamu (2018) explains how qualitative methods are often associated with interpretivist approach and subjectivist techniques in the collection and analysis of data in information system research. Goldkuhl's (2012) explanation that the interpretivist aims to gain an understanding of the meanings that are subjectively associated with things, which is another rationale for selecting the approach for this study. According to Walsham (2006), the interpretive approach is used to adopt our knowledge of reality that is consciously or unconsciously constructed by human actors in information systems research.

As shown in Table 1, a total of 54 existing literature in the areas of data, information, data architecture and information architecture were gathered and used as the data for the study. Owing to the areas of focus which has been evolving rapidly over the years, I decided to collect literature of the past 10 years, from 2008 to 2018 . This was to have a balanced view 
TABLE 1: Data collection.

\begin{tabular}{llc}
\hline Topic & Focus area & Number \\
\hline Data and data architecture & Definition and scope & 8 \\
& Characteristics and development & 6 \\
& Use and management & 6 \\
Information and & Definition and scope & 9 \\
information architecture & Characteristics and development & 4 \\
& Use and management & 8 \\
\hline Data and information & Differences between data and information & 13 \\
\hline Total & - & $\mathbf{5 4}$ \\
\hline
\end{tabular}

of how the terms have been used and applied, as well as the meanings that have been associated with the concepts of data and information architectures over the past 10 years. According to Iyamu, Nehemia-Maletzky and Shaanika (2016), a spread of historical views helps to gain an understanding of the consistency of meanings that are associated with a concept, including the challenges and confusions that that manifested. Table 1 presents a summary of data that were collected.

The choices of the topics as stated in Table 1 were reached based on the objective of the research, which is to address the confusion caused by the loose and interchangeable use of the concepts 'data architecture' and 'information architecture'. The topics had to be spread in such a manner because both academic and practitioners are not consistent in their use of the terminologies that are associated with the concepts. Commonly used terminology or semantics of meaning contributes to confusion between the concepts of data and information (Iyamu 2011). Each of the topics was expanded relative to the context of the study, purposely to ensure comprehensive coverage. The focus areas were intended to be more precise incomprehension. For example, it would not have been possible to address the confusion without an understanding of the definitions (descriptions), scope (boundaries) and use of these concepts.

The data was collected from three main databases: Google Scholar, EBSCOhost and ProQuest, which are most popular for finding IS research materials. Five keywords were primarily used for the search of articles: 'data', 'data architecture', 'information', 'information architecture' and 'data and information architectures'. In the analysis of the data, I applied the hermeneutic technique from the perspective of interpretivist approach. The approach was very useful because it allows subjective examining of data, which leads to an in-depth understanding of the phenomenon being studied. The use of hermeneutics technique as an interpretive approach is appropriate for understanding various types of texts (Prasad 2002).

\section{Analysis: Data and information architectures}

The hermeneutics technique from an interpretivist perspective was employed in the analysis of the data. This allows

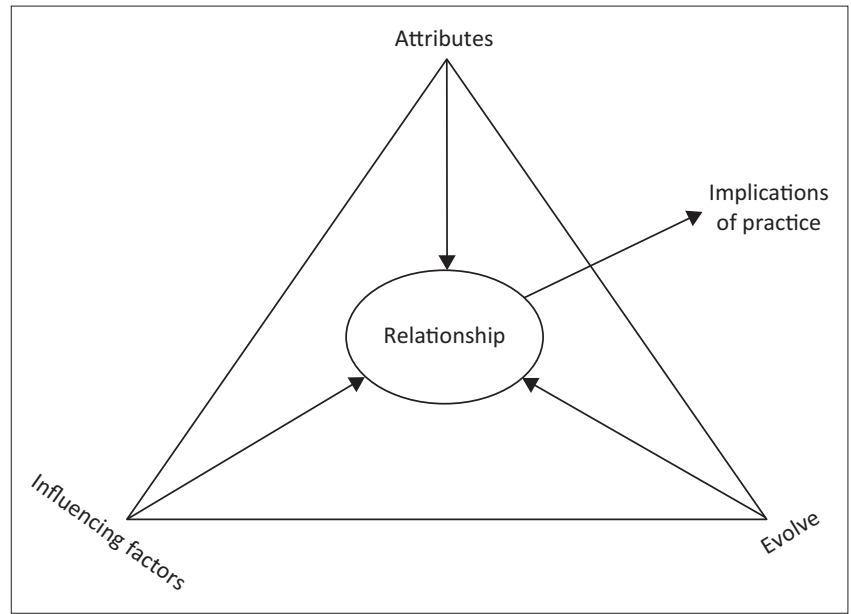

FIGURE 1: Connecting the confusion between data and information architecture.

subjective reasoning towards achieving the objective of the study. The analysis focused on three main components: (1) attributes, (2) influencing factors and (3) evolve, as shown in Figure 1. These components help to connect the confusion between the data and information architectures, through an understanding of the relationship that they share. As discussed further, the three components can be fundamental in gaining a better understanding about the confusion between data and information architectures in an organisation.

The three components are briefly discussed, followed by detail analysis:

- The attributes of the concepts - the attributes of both data and information architectures were identified. This helped to understand what each concept comprises. As shown in Table 1, the attributes are state of originality, associated terms and catalogue.

- Evolving characteristics of the concepts - from the analysis, reproductive and refinement were the two main factors through which both data and information architectures evolve. This is particularly from the perspectives of development, use and management.

- Influencing factors - six factors were found to be the main influence in the ways in which the concepts of data and information architectures are developed, used and managed. The factors were identified from the three attributes discussed in Table 2, which are requirements, differentiation, confusion, source, characteristics and purpose. The factors are discussed below, and they should be read with the attributes (Table 2) to gain a better understanding of the concepts towards clarifying the confusion between them.

\section{Attributes of data and information architectures}

As shown in Table 2, there are three main attributes in the course of differentiating data architecture from the information architecture: state of originality, associated terms and catalogue. These attributes, as presented in 
TABLE 2: Data and information architecture.

\begin{tabular}{|c|c|c|}
\hline Attribute & Data architecture & Information architecture \\
\hline $\begin{array}{l}\text { State of } \\
\text { originality }\end{array}$ & $\begin{array}{l}\text { The original state of data is rawness. Based on the rawness of data, the } \\
\text { architecture is used to describe a set of models, standards and principles, } \\
\text { which dictates the collection, storage, usage and integration of data in a } \\
\text { data system (You et al. 2015). In an organisation, the data architecture is } \\
\text { designed in a way that it can describe artefacts about systems, and how } \\
\text { the artefacts share the resources and interaction between them within } \\
\text { an environment (Nielsen \& Parui 2011). }\end{array}$ & $\begin{array}{l}\text { Information begins from the state of refinement. Information architecture is a set of } \\
\text { several elements of the information about infrastructures and activities of a business, } \\
\text { which include business model and processes (Samihardjo 2015). Information } \\
\text { architecture is defined by, and developed based on, an organisation's data, to rapidly and } \\
\text { consistently provide the stakeholders with the necessary information (Affeldt \& Junior } \\
\text { 2013). According to Alhefeiti and Nakata (2017), information architecture is the } \\
\text { collection of rules and regulations that guide the collection, storage, processing, } \\
\text { usage and sharing of information within an organisation. }\end{array}$ \\
\hline $\begin{array}{l}\text { Associated } \\
\text { terms }\end{array}$ & $\begin{array}{l}\text { There are big data, which means that we could soon have big data } \\
\text { architecture. Data architecture covers the flow of data in an organisation. } \\
\text { Hoven (2003) states that data architecture is fundamental in an enterprise } \\
\text { or organisational environment where there are several data sources to be } \\
\text { managed. Thus, the focus of data architecture is to understand the flow of } \\
\text { data across multiple systems in the organisation, the source, maintenance, } \\
\text { sharing, updates and storage of the data (Fleckenstein \& Fellows 2018). }\end{array}$ & $\begin{array}{l}\text { The questions are: can information be big? Can we say big information architecture? The } \\
\text { answers, at least for now, are no. Information architecture is often developed to facilitate } \\
\text { the management, access and use of large amounts of information that is available to an } \\
\text { organisation (Resmini \& Rosati 2012). The architecture covers the design of single and } \\
\text { multiple information spaces and provides standards for information usage and } \\
\text { management (Ding et al. 2017; Joudrey \& Taylor 2017). }\end{array}$ \\
\hline Catalogue & $\begin{array}{l}\text { Each business has its own policies and needs that guide how data is } \\
\text { organised by using architecture (Crespo \& Santos 2015). Therefore, the } \\
\text { elements of data architecture will most often depend on the type of } \\
\text { business activities and its needs. Thus, in an organisation, data architecture } \\
\text { catalogue should include data glossary, models, data lifecycle diagrams, } \\
\text { standards, policies, rules and data asset inventory (Fleckenstein \& Fellows } \\
\text { 2018; You et al. 2015). }\end{array}$ & $\begin{array}{l}\text { Information architecture is an umbrella term that covers all elements of data architecture } \\
\text { and other architectures. Samihardjo (2015) states that the key elements of information } \\
\text { architecture are: (1) data architecture, (2) system architecture and (3) computer } \\
\text { architecture. In software development, information architecture includes models for the } \\
\text { activities, which will be carried out during development, and the technologies, with the } \\
\text { focus on usability to facilitate the development of useful software (Rojas \& Macías 2015). }\end{array}$ \\
\hline
\end{tabular}

Table 2, help to differentiate between the concepts of data and information architecture.

\section{Evolving nature of data and information architectures}

In the context of architecture, data and information continue to evolve through refinement and reproductive approaches. As shown in Figure 2, the relationship between data and information architecture implies the concepts wholly depend on each other, and neither one can exist by itself. At the same time, by virtue of the concepts' nearness to each other, they cannot coexist in an environment.

The evolving nature of both data and information architectures is transformative, in that the refinement of one results in the other. The transformation has no end, as long as one of the entities (data or information) exists. The two components, refinement and reproduction that form the transformative approach are discussed below.

\section{Refinement}

As stated many times in this article, the term 'data' is different from 'information' even though they have often been used interchangeably. According to Grabara et al. (2014:1), very often the term 'data' has been defined as 'information processed by a computer', and 'information' has been defined as 'data processed by a computer'. This interpretation can be misleading because if we look at these concepts in a hierarchic structure, data exists before information (Grabara et al. 2014:1). Therefore data needs to be refined to be considered information (Vick et al. 2015).

Data are raw facts that are meaningless; therefore, they cannot be considered right or wrong (Fisher 2016). Therefore, to draw meaning out of the data, the refinement process takes place. Refinement of data is basically transforming raw facts into meaningful entities, which are then considered information. This involves processing or analysing the data in a way that it results in an understanding of what it is meant by what we read or listen to (Rein \& Biermann 2013).

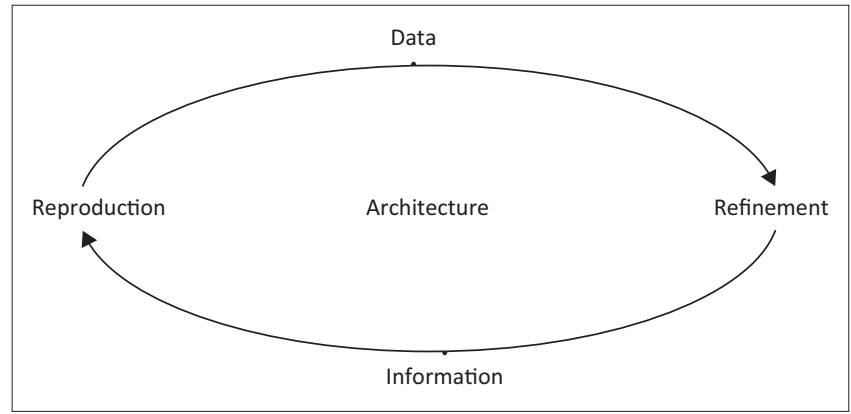

FIGURE 2: The evolving nature of data and information.

\section{Reproductive}

Refined data are considered information because they result in meaningful facts. However, what is considered information (meaningful facts) in one environment is not necessarily information within another environment. This is mainly because the meaning of data or information depends on the context in which it is used (Rein \& Biermann 2013). Fisher (2016) claims that data is often processed and put into an understandable context and is only then considered information. Therefore, depending on the context, there is a possibility that whatever has been processed and considered information in one environment may be considered data on another. Therefore, it will be required to be processed again to be considered information within a different environment making the distinction very difficult (Grabara et al. 2014). Additionally, Kitchin (2014) states that context is one of the influencing factors in the existence, processing, management, analysis and storage of data. Therefore, there is a loop in which data become information and information become data again depending on the context. This is also known as production and reproduction within the context of structuration theory.

Structuration theory emphasises the production and reproduction of social systems (Chang 2014). This happens through the interaction between agents (technical and nontechnical) and structure (rules and resources). This means that agents make use of rules and resources for the production 
and reproduction of social systems, which then influence the interaction between agents and structure (Iyamu 2013). This influence can either be a constraining or enabling factor for agents' actions (Giddens 1984). Thus, it creates an endless loop, similar to the refinement and reproduction of data and information, which makes differentiating between the terms even more complex (Grabara et al. 2014). This complexity affects the understanding of data and information architecture (Rossi \& Hirama 2015). However, these two terms (data and information architectures) can be clarified and understood by clearly laying out their requirements, purpose and characteristics.

\section{Factors of influence between data and information architectures}

In view of the attributes, as summarised in Table 2, four factors were found to influence the differentiation between the data and information architectures, which help to understand the confusion between the two concepts. The factors are requirements, purpose, source and characteristics. Through subjective understanding and examination of the confusion, we were able to differentiate between the architectures in the discussion that follows.

\section{Requirements}

Based on the similarity between data and information architectures, the same requirements can with ease be gathered and used for the concepts, even though that might not be the intention. An example and reference can be drawn from Colati (2018) who argued that policies can be combined for data architecture and information architecture to develop a strategic framework. Despite this possibility, both data architecture and information architecture have different types of requirements for an organisation's purposes (Crespo \& Santos 2015).

Through systems and technologies, information is obtained from multiple data sources (Affeldt \& Junior 2013), which confirms that data exists before information. However, information may become data, as shown in Figure 2, depending on the phenomenon being monitored or studied. The evolving nature of both data and information can be influenced by factors such as time. This shapes the requirements, which defines the architecture.

Over the years, the volume of data has increased and new requirements for data architecture have emerged (Bakshi 2012). In the same line of thought, You et al. (2015) suggested that the following could be the emerging requirements for data architecture: large capacity, high interactive speed, high reliability and well-designed metadata. In addition, Fleckenstein and Fellows (2018) claim that some of the critical data architecture requirements for an organisation include data governance, privacy and security. However, privacy and security are also critical requirements for information architecture. This is mainly because data architecture is one of the elements of information architecture (Samihardjo 2015).
In general, information architecture focuses on facilitating access and management of information in an organisation (Resmini \& Rosati 2012). Chen and Lin (2014) state that usability and accessibility are some of the main requirements of information architecture. This means that the information should be easy to access and of high quality (Toure et al. 2016). These requirements should be met to make the information usable for the users.

\section{Purposes}

In today's digital world, a large amount of data is stored in digital libraries and often accessed through search engines. Chen and Lin (2014) claim that the digital library is the entity that enables the growth of information. Digital libraries are established and enhanced by information architecture by reducing search time (Chen \& Lin 2014). Thus, Dillon and Turnbull (2010) state that information architecture optimises the search engines and accessibility to information. This current situation helps to reshape the purpose of information architecture in an environment.

Based on the details provided in the scope as presented and discussed before, data cannot be used to achieve the organisation's goal and objectives because it is raw. The question is how is architecture developed or provided for a raw data entity? Information architecture is increasingly being developed and implemented to achieve the needs of an organisation and promotes its competitive advantages (Resmini \& Rosati 2012). According to Pessoa et al. (2015), this is possible because information architecture facilitates strategic decision-making within organisations by turning the complex into clear and understandable information. The architecture, therefore, enables standardisation, ease of access, increased usefulness and ease of management (Pessoa et al. 2015).

Similar to information architecture, generally organisations make use of data architecture to facilitate the management of a large amount of data. According to Bakshi (2012), the purpose of data architecture is not limited to the storage and management of data. The author suggests that the data architecture should provide tools to analyse and extract meaning out of the data (information). Hoven (2003) claims that a data architecture enables the effective use of data and enhances the integration of data in two ways: (1) to get a better understanding of the organisation's performance and (2) to get a better combination of the organisation's customers' and stakeholders' data. However, Fleckenstein and Fellows (2018) claim that the purpose of data architecture is a deeper concept including the ability to extract trusted information from a network of architectures.

\section{Confusion}

The confusion often begins with a question that is consciously asked: when it is data and when does it become information? Data remain data, a set of data or big data when it is impossible or difficult to make sense of it. Once meaning can 
be generated from, or associated with the data, it becomes a piece of information. Thereafter, the architecture is defined.

Additionally, the term 'information architecture' is used within two different contexts, namely websites and organisations. Within the website context, the term information architecture refers to the way digital information is structured to optimise search engines and speed up the access to information online (Chen \& Lin 2014). This is different from the organisational context. Within the organisational context, information architecture is a much deeper concept. Information architecture in the organisation involves data standards for well-structured and accessible information to facilitate decision-making (Pessoa et al. 2015). This is not different from data architecture. In fact, both information architecture and data architecture involve providing structure for the information that is used within an organisation (Molnár \& Vincellér 2013).

However, it is confusing whenever one is referring to information architecture for websites or in the organisational context. This confusion comes from the use of the term information architecture within two different contexts without clearly stating the context. This is what makes some aspiring architects and those who are not IT specialists think that information architecture and data architecture are two different subject areas.

As stated many times in this article, data architecture is a subset of information architecture (Samihardjo 2015). Therefore, the two terms cannot be referred to on their own. However, the terms are often used interchangeably to mean the other. For example, many times data architecture is used to refer to information architecture and vice versa. This confuses aspiring architects, none-IT specialists and the people who write about information and data architecture.

\section{Characteristics}

The characteristics of a data or information architecture vary from business to business depending on the need and objectives. However, in general, data architecture is constituted by models, data standards, principles for data management, policies, rules, data glossaries, data lifecycle diagrams and data storage (You et al. 2015; Fleckenstein \& Fellows 2018). Information architecture constitutes all the same elements of data architecture plus other subsets. According to Samihardjo (2015), information architecture consists of data architecture, system architecture and computer architecture.

\section{Implications for practice}

The loose and interchangeable use of the terms 'data architecture' and 'information architecture' have implications in practice, for IS/IT managers, architects as well as the business managers. As revealed from the analysis, the primary implications in practice are in the areas of information systems design, management, as discussed in Table 3.
TABLE 3: Implications of practice.

\begin{tabular}{ll}
\hline Factor & Description \\
\hline Evolve & $\begin{array}{l}\text { Information comes from data, which makes the latter original. } \\
\text { The relationship between data and information is iterative. } \\
\text { With this understanding, the requirements for information or data } \\
\text { architectures can be better sourced, and the definition, development } \\
\text { and implementation of the architectures can be clarified for an } \\
\text { organisation's purposes. Thus, in practice, this has implication for } \\
\text { how the artefacts of the terms are classified and categorised. }\end{array}$ \\
Development & $\begin{array}{l}\text { In practice, the confusion about data and information architecture } \\
\text { has implication on both an organisation and individual, from a } \\
\text { development perspective. In an organisation, the implication affects } \\
\text { the structure, and allocation of roles and responsibilities to the } \\
\text { specialists, data architecture or information architecture. At the } \\
\text { individual level, the confusion hampers career development in that } \\
\text { some of the specialists are not convinced on the path to follow. }\end{array}$ \\
Enterprise & $\begin{array}{l}\text { Many organisations are confused about whether to include data or } \\
\text { information architecture as a domain in the development and } \\
\text { architecture } \\
\text { implementation of enterprise architecture (EA). As a result, the } \\
\text { terms are often loosely or interchangeably used or referred to in EA. }\end{array}$ \\
$\begin{array}{l}\text { The implication is that each domain (data or information) stands on } \\
\text { its own. Therefore, the content of one domain affects other } \\
\text { domains, such as application, business and technology, in their } \\
\text { development and implementation. }\end{array}$ \\
\hline
\end{tabular}

As summarised in Table 3, an understanding of the characteristic elements that differentiate and create confusion between the terms data and information can help define a clearer architecture for an organisation. This includes having an appropriate resource to develop and manage the concepts. Additionally, architects will be appropriately employed and assigned roles and responsibilities, which limits confusions and conflicts within the organisational structure.

\section{Conclusion}

This study was undertaken to examine the implication of practice in the loose and interchangeable use of the terms 'data' and 'information' architectures within an organisation. In achieving the objective of the study, the qualitative methods were employed in the study. Qualitative data was collected from existing literature in the areas of data and information architecture. The data was interpretively analysed. From the analysis, four factors were found to be influencing the differentiation between data and information architectures. The factors are requirements, purpose, source and characteristics. Thus, this study provides a clear differentiation between 'data' architecture and 'information' architecture to overcome the loose and interchangeable use of the terms. The study will be of benefit to organisations, in that it will facilitate decision-making, definition, development and implementation of the domains of data and information architectures. This study will also contribute to academia through the addition to the existing literature and as a teaching and learning material.

Although the researchers believe that the four factors (requirements, purpose, source and characteristics) were thoroughly discussed, there is still room for further research on this topic. An example could be the application of social theories, such as structuration theory, activity theory and actor network theory. The researcher strongly believes that looking at the same data with different lenses can bring out new things that were missed during the analysis without a lens, as well as different perspectives to the research topic. 


\section{Acknowledgements}

The author would like to thank the research assistant, Maria Mutudi, members of his research forum and the Department of Information Technology at Cape Peninsula University of Technology, Cape Town.

\section{Competing interests}

The author declares that he has no financial or personal relationships that may have inappropriately influenced him in writing this article.

\section{Author's contribution}

I declare that I am the sole author of this research article.

\section{Ethical consideration}

This article followed all ethical standards for carrying out research without direct contact with human or animal subjects.

\section{Funding}

This research received no specific grant from any funding agency in the public, commercial or not-for-profit sectors.

\section{Data availability statement}

Data sharing is not applicable to this article as no new data were created or analysed in this study.

\section{Disclaimer}

The views and opinions expressed in this article are those of the authors and do not necessarily reflect the official policy or position of any affiliated agency of the authors.

\section{References}

Aamodt, A. \& Nygård, M., 1995, 'Different roles and mutual dependencies of data, information, and knowledge - An Al perspective on their integration', Dato Knowledge Engineer 16(3), 191-222. https://doi.org/10.1016/0169-023X(95) 00017-M

Affeldt, F.S. \& Junior, S., 2013, 'Information architecture analysis using business intelligence tools based on the information needs of executives', JISTEM-Journal of Information Systems and Technology Management 10(2), 251-270. http://doi. org/10.4301/S1807-17752013000200004

Alhefeiti, A. \& Nakata, K., 2017, 'A framework for information-sharing analysis based on activity theory', in Proceedings of the 3rd international conference on communication and information processing, ACM, Tokyo, pp. 151-157.

Bakshi, K., 2012, 'Considerations for big data: Architecture and approach', in Aerospace conference, Big sky, IEEE, pp. 1-7.

Chang, C.L., 2014, 'The interaction of political behaviors in information systems implementation processes - Structuration theory', Computers in Human Behavio 33(21), 79-91. https://doi.org/10.1016/j.chb.2013.12.029

Chen, C.M. \& Lin, S.T., 2014, 'Assessing effects of information architecture of digital libraries on supporting E-learning: A case study on the digital library of nature \& culture', Computers \& Education 75, 92-102. https://doi.org/10.1016/j.compedu. 2014.02.006

Chipangura, P., Van Niekerk, D. \& Van Der Waldt, G., 2016, 'An exploration of objectivism and social constructivism within the context of disaster risk', Disaster Prevention and Management 25(2), 261-274.

Colati, G., 2018, 'A data architecture for library collections', Journal of Library Administration 58(5), 468-481. https://doi.org/10.1080/01930826.2018.1468660

Crespo, P. \& Santos, V., 2015, 'Construction of integrated business management systems for micro and small enterprises', Revista Iberica de Sistemas e Tecnologias de Informacao $15,35-50$
Dillon, A. \& Turnbull, D., 2010, 'Information architecture', Encyclopedia of Library and Information Science 1(1), 2361-2368.

Ding, W., Lin, X. \& Zarro, M., 2017, 'Information architecture: The design and integration of information spaces', Synthesis Lectures on Information Concepts, Retrieval, and Services 9(2), 152. https://doi.org/10.2200/S00755ED2V01Y201701ICR056

Farwick, M., Breu, R., Hauder, M., Roth, S. \& Matthes, F., 2013, 'Enterprise architecture documentation: Emperical analysis of information sources for automation', in System sciences (HICSS), 46th Hawaii international conference on IEEE, Wailea, pp. 3868-3877.

Fisher, M., 2016, 'Develop a data system for your pilot plant', Chemical Engineering Progress 112(10), 43-47.

Fleckenstein, M. \& Fellows, L., 2018, Modern data strategy, Cham, Springer.

Giddens, A., 1984, The constitution of society: Outline of the theory of structuration, Berkeley, University of California Press.

Goldkuhl, G., 2012, 'Pragmatism vs interpretivism in qualitative information systems research', European Journal of Information Systems 21(1), 135-146. https://doi. org/10.1057/ejis.2011.54

Grabara, J., Kolcun, M. \& Kot, S., 2014, 'The role of information systems in transport logistics', International Journal of Education and Research 2(2), 1-8.

Hinkelmann, K., Gerber, A., Karagiannis, D., Thoenssen, B., Van Der Merwe, A. \& Woitsch, R., 2016, 'A new paradigm for the continuous alignment of business and IT: Combining enterprise architecture modelling and enterprise ontology' Computers in Industry 79, 77-86. https://doi.org/10.1016/j.compind.2015. 07.009

Hoogervorst, J.A. \& Dietz, J.L., 2015, 'Enterprise architecture in enterprise engineering', Enterprise Modeling and Information Systems Architectures 3(1), 3-13. https:// doi.org/10.18417/emisa.3.1.1

Hoven, J.V.D., 2003, 'Data architecture: Blueprints for data', Information Systems Management 19(4), 90-92. https://doi.org/10.1201/1078/43203.20.1.20031201/ 40089.12

Iannuzzi, D., Grant, A., Corriveau, H., Boissy, P. \& Michaud, F., 2016, 'Specification of an integrated information architecture for a mobile teleoperated robot for home telecare', Informatics for Health and social Care 41(4), 350-361. https://doi.org/1 0.3109/17538157.2015.1033527

Inmon, W. \& Linstedt, D., 2014, Data architecture: A primer for the data scientist: Big data, data warehouse and data vault, 1st edn., S. Elliot (ed.), Morgan Kaufmann, Waltham, MA.

Iyamu, T., 2011, 'The architecture of information in organisations', South African Journal of Information Management 13(1), 1-9. https://doi.org/10.4102/sajim v13i1.419

Iyamu, T., 2013, 'Underpinning theories: Order-of-use in information systems research', Journal of Systems and Information Technology 15(3), 224-238. https:// doi.org/10.1108/JSIT-11-2012-0064

Iyamu, T., 2014, Information technology enterprise architecture: From concept to practice, 2nd edn., Heidelberg Press, Melbourne.

Iyamu, T., 2018, 'Collecting qualitative data for information systems studies: The reality in practice', Education and Information Technologies 23(5), 2249-2264. https://doi.org/10.1007/s10639-018-9718-2

Iyamu, T., Nehemia-Maletzky, M. \& Shaanika, I., 2016, 'The overlapping nature of Business Analysis and Business Architecture: What we need to know', Electronic Journal of Information Systems Evaluation 19(3), 169-179.

Joudrey, D.N. \& Taylor, A.G., 2017, The organization of information, 4th edn., ABCCLIO Publication, Santa Barbara, CA.

Kanehisa, M., Goto, S., Sato, Y., Kawashima, M., Furumichi, M. \& Tanabe, M., 2013, 'Data, information, knowledge and principle: Back to metabolism in KEGG', Nucleic Acids Research 42(D1), D199-D205. https://doi.org/10.1093/nar/ gkt1076

Kitchin, R., 2014, 'The real-time city ? Big data and smart urbanism', GeoJournal 79(1), 1-14. http://doi.org/10.2139/ssrn.2289141

Mark, R. \& Krishna, D., 2014, 'Risk management', in M.S. Brose, M.D. Flood, D. Krishna \& B. Nichols (eds.), Handbook of financial data and risk information - Volume I: Principals and context, pp. 33-74, Cambridge University Press, London.

Marshall, C., Brereton, P. \& Kitchenham, B., 2015, 'Tools to support systematic reviews in software engineering: A cross-domain survey using semi-structured interviews', in Proceedings of the 19th international conference on evaluation and assessment in software engineering, ACM, p. 26.

Miller, S., 2014, 'Collaborative approaches needed to close the big data skills gap', Journal of Organization Design 3(1), 26-30. https://doi.org/10.7146/jod.9823

Mohammad, A., Mcheick, H. \& Grant, E., 2014, 'Big Data architecture evolution: 2014 and beyond', in Proceedings of the fourth ACM international symposium on Development and analysis of intelligent vehicular networks and applications, ACM, pp. 139-144.

Molnár, B. \& Vincellér, Z, 2013 'Comparative study of Architecture for Twitter Analysis and a proposal for an improved approach', in 2013 IEEE 4th Internationa Conference on Cognitive Infocommunications (CogInfoCom), IEEE, Budapest, Hungary, December 2-4, 2013, pp. 11-16.

Nielsen, P. \& Parui, U., 2011, Microsoft SQL server 2008 bible, Canada, John Wiley \& Sons.

Palinkas, L.A., Horwitz, S.M., Green, C.A., Wisdom, J.P., Duan, N. \& Hoagwood, K. 2015, 'Purposeful sampling for qualitative data collection and analysis in mixed method implementation research', Administration and Policy in Mental Health and Mental Health Services Research 42(5), 533-544. https://doi.org/10.1007/ s10488-013-0528-y 
Pessoa, C.R.M., Baracho, R.M.A., Erichsen, M.N. \& Jamil, G.L., 2015, 'Information architecture: Case study', in G.L. Jamil (ed.), Information architecture and management in modern organizations, IGI Global, Hershey, PA.

Pras, A. \& Schönwälder, J., 2003, On the difference between information models and data models (No. RFC 3444), pp. 1-8, The Internet Society, Reston, VA.

Prasad, A., 2002, 'The contest over meaning: Hermeneutics as an interpretive methodology for understanding texts', Organizational Research Methods 5(1), 12-33. https://doi.org/10.1177/1094428102051003

Rein, K. \& Biermann, J., 2013, 'Your high-level information is my low-level data a new look at terminology for multi-level fusion', in Information Fusion (FUSION), 16th international conference on IEEE, pp. 412-417.

Rojas, L.A. \& Macías, J.A., 2015 'An agile information-architecture-driven approach for the development of user-centered interactive software', in Proceedings of the XVI international conference on human computer interaction, p. 8, ACM, New York.

Resmini, A. \& Rosati, L., 2012, 'A brief history of information architecture', Journal of information architecture $3(2), 33-45$

Rossi, R. \& Hirama, K., 2015, 'Characterizing big data management', Issues in Informing Science and Information Technology 12, 165-180.

Safari, H., Faraji, Z. \& Majidian, S., 2016, 'Identifying and evaluating enterprise architecture risks using FMEA and fuzzy VIKOR', Journal of Intelligent Manufacturing 27(2), 475-486. https://doi.org/10.1007/s10845-014-0880-0
Saint-louis, P., Morency, M.C. \& Lapalme, J., 2017, 'Defining enterprise architecture: A systematic literature review', in Enterprise distributed object computing workshop (EDOCW), IEEE 21st International IEEE, pp. 41-49.

Samihardjo, R., 2015, 'Perancangan arsitektur informasi organisasi pendidikan menggunakan business system planning', Jurnal Ilmiah Teknologi Informasi Terapan 2(1), 60-68.

Shaw, S., Vermeulen, A.F., Gupta, A. \& Kjerrumgaard, D., 2016, 'Hive architecture', in Practical hive, pp. 37-48, Berkeley, Apress.

Soanes, C., 2002, The compact Oxford English Dictionary of current English, 2nd edn., London, Oxford University Press.

Toure, C.E., Michel, C. \& Marty, J., 2016, 'Re-designing knowledge management systems: Towards user-centred design methods integrating information architecture', Computer Science Human Computer Interaction 1, 7-8.

Vick, E., Nagano, S.M. \& Popadiuk, S., 2015, 'Information culture and its influences in knowledge creation: Evidence from university teams engaged in collaborative innovation projects', International Journal of Information Management 35(3), 292-298. https://doi.org/10.1016/j.ijinfomgt.2015.01.010

Walsham, G., 2006, 'Doing interpretive research', European Journal of Information Systems 15(3), 320-330. https://doi.org/10.1057/palgrave.ejis.3000589

You, S., Zhu, L., Liu, Y., Robertson, R., Liu, Y., Shankar, M. et al., 2015, 'Data architecture for the next-generation power grid: Concept, framework, and use case', in Information science and control engineering (ICISCE), 2nd international conference, IEEE, pp. 679-682. 